\title{
Desinformação e competência em informação: discussões e possibi- lidades na Arquivologia
}

\author{
Disinformation and information literacy: discussions and possibilities in Archival science
}

\author{
Ana Roberta Pinheiro Moura \\ Graduada em Arquivologia \\ Universidade Federal do Pará \\ anarobertam4@gmail.com \\ Renata Lira Furtado \\ Doutora em Ciência da Informação \\ Universidade Federal do Pará \\ re23br@gmail.com \\ Regina Célia Baptista Belluzzo \\ Doutora em Ciências da Comunicação \\ Universidade Estadual Paulista \\ rbelluzzo@gmail.com
}

\section{Resumo}

A presente pesquisa teve como objetivo mapear as possíveis interseções entre o fenômeno Desinformação, a temática Competência em Informação e a Arquivologia no cenário nacional. O estudo foi desenvolvido por meio da Revisão Bibliográfica Sistemática na Base de Dados Referenciais de Artigos de Periódicos em Ciência da Informação - BRAPCI. Os resultados identificaram escassez de produção acadêmico-cientifica relacionando a Competência em Informação com a Arquivologia e no que tange à tríade Desinformação, Competência em Informação e Arquivologia não foi identificada nenhuma ocorrência, contudo evidencia-se a relação existente entre a Competência em Informação e a Desinformação no âmbito da Ciência da Informação. O resultado desta pesquisa pode contribuir de forma significativa tanto para a Arquivologia e Ciência da Informação como para a sociedade em geral, considerando que o fenômeno Desinformação ainda é pouco compreendido e vem de maneira genérica assolando a sociedade. Os resultados obtidos foram relevantes para confirmar que os preceitos da Competência em Informação, especialmente na perspectiva crítica, configuram-se como uma possibilidade tanto de combate, como de redução da desinformação na sociedade e no contexto arquivístico, sendo que a disseminação e a preservação de fake news bem como de outras formas de desinformação, poderão acarretar danos irreparáveis para a sociedade futura.

\section{Palavras-chave}

Arquivologia. Desinformação. Fake news. Competência em informação. Revisão bibliográfica sistemática.

\begin{abstract}
The present research had the objective of mapping the possible intersections between the Disinformation phenomenon, the Information Literacy theme and the Archival Science in the national scenario. The study was developed through the Systematic Bibliographic Review in the Reference Database of Periodical Articles in Information Science - BRAPCI. The results identified a low academic-scientific production, relating Information Literacy to Archival Science, and in relation to the triad Disinformation, Information Literacy and Archival Science, no occurrence was identified, but the relationship
\end{abstract}


between Information Literacy and Disinformation in the scope of Information Science. The result of this research can contribute significantly to both the Archives and Information Science as well as to society in general, considering that the Disinformation phenomenon is still poorly understood and comes in a general way devastating society. The results obtained were relevant to confirm that the Information Literacy especially in the critical perspective, precepts are a possibility both of combat, of reducing the disinformation in society and in the archival context, the dissemination and preservation of fake news as well as other forms of disrepair, could lead to irreparable damage to the future society.

\section{Keywords}

Archival Science. Disinformation. Fake news. Information literacy. Systematic bibliographic review.

\section{INTRODUÇÃO}

Com a ampla disseminação de informações proporcionada pela massificação dos recursos tecnológicos na sociedade contemporânea, é comum nos depararmos com informações adulteradas disseminadas nos mais diversos meios de comunicação. A literatura atribuiu a esse fenômeno o termo Disinformation ou sua tradução em português "Desinformação", como sendo uma informação falsa, enganosa e/ou imprecisa, que pode ser criada propositalmente com prejuízo a alguém ou erroneamente.

A publicação do Relatório da Comissão Europeia, produzido em Bruxelas, em 26 de abril de 2018, intitulado "Tackling online disinformation: a European Approach"1 (COMISSÃO EUROPEIA, 2018), apresenta a Competência em Informação (Colnfo) como uma alternativa para diminuir a Desinformação, considerando ser a Colnfo uma habilidade para gerenciamento da informação de forma crítica e reflexiva e uma forma de avaliar o contexto da informação através de estudos das fontes (ZATTAR, 2017).

Desenvolvida inicialmente na Biblioteconomia, a Competência em Informação surgiu como suporte na qualificação dos usuários, para ajudá-los a melhorar a forma de recuperação da informação nas bibliotecas. A discussão em torno dessa temática migrou para a Ciência da Informação e, atualmente, se inicia no Brasil uma corrente de pesquisadores discutindo a Colnfo no âmbito da Arquivologia, com foco na formação e atuação dos arquivistas e nos usuários dos arquivos, considerando, além do seu objeto - a informação arquivística, questões específicas que visam o acesso, a compreensão e o uso da informação (FARIAS, 2018).

Nesse contexto, este estudo busca apresentar a Competência em Informação e a Desinformação como temas pertinentes para desenvolvimento de pesquisas na Arquivologia, considerando as especificidades de cada um dos temas sobre o elemento Informação. Dessa forma o objetivo é identificar por meio de uma Revisão Bibliográfica Sistemática (RBS) pontos de interseção entre os temas, visando a ampliação do espectro de discussão da Arquivologia nacional, com elementos que escapam ao que se considera o núcleo duro da ciência arquivística: a organização e a representação da informação arquivística.

\section{DESINFORMAÇÃO, COMPETÊNCIA EM INFORMAÇÃO E ARQUIVOLOGIA}

Ainda que seletivo, o presente referencial teórico parte do ponto de convergência comum aos três elementos apresentados nesse estudo: a informação, termo usado cotidia-

\footnotetext{
${ }^{1}$ COMISSÃO EUROPÉIA. Combater a desinformação em linha: uma estratégia europeia. Bruxelas, 26 abr. 2018. Disponível em: https://eur-lex.europa.eu/legal-content/PT/TXT/HTML/?uri=CELEX:52018DC0236\&from=EN. Acesso em: 2 nov. 2018.
} 
namente pela maioria das pessoas que acreditam empregá-lo de forma correta. Além disso, de difícil definição e até mesmo de obtenção de consenso sobre como deveria ser definido, o termo informação pode significar coisas diferentes para pessoas diferentes, em contextos diferentes. No contexto desta pesquisa adotou-se a definição de Barreto (1994) que conceitua a informação como uma estrutura significante com a competência de gerar conhecimento para o indivíduo e seu grupo.

A fim de complementar essa definição e aliar elementos que embasem esse referencial, recorreu-se à abordagem filosófica de Floridi $(2011,2012)$ que se ocupa em entender dentre outras questões em torno da informação e da sua veracidade, como as informações devem ser adequadamente criadas, processadas, gerenciadas e utilizadas, o que acontece quando o processo de informação é defeituoso e o quanto informações falsas, imprecisas e enganosas podem ser extremamente perigosas, fenômeno que ele conceitua como pseudoinformação ou desinformação, caracterizado pelo autor como um grande guarda-chuva conceitual que abarcaria também a informação direcionada e o ato de enganar propositalmente.

A desinformação é uma forma particularmente problemática de informação, é a informação que desinforma, que visa alienar, que não acontece ao acaso, ao contrário de um erro honesto, a desinformação vem de alguém que está ativamente envolvida em uma tentativa de enganar (FETZER, 2004; PIPER, 2002). A primeira noção do conceito surgiu no contexto das práticas de guerra. Fallis (2015) faz referência ao Operation Bodyguard na Segunda Guerra Mundial, que visava preservar a localização do Dia D. Já Volkoff (2004 apud ZATTAR, 2017) remete ao russo dezinformatsiya do período pós-Segunda Guerra Mundial como uma prática capitalista para submissão da população. No idioma inglês, o autor indica o surgimento da palavra disinformation no dicionário Chambers twentieth century, em 1972.

A desinformação pode ser entendida como informação comprovadamente falsa ou enganadora que é criada, apresentada e divulgada para obter vantagens econômicas ou para enganar deliberadamente o público e que é suscetível de causar um prejuízo público que abrange ameaças aos processos políticos democráticos e aos processos de elaboração de políticas, bem como a bens públicos (COMISSÃO EUROPEIA, 2018).

Segundo o Relatório da Comissão Europeia a proliferação da desinformação tem causas econômicas, tecnológicas, políticas e ideológicas interligadas. O documento aponta que a propagação da desinformação é sintoma de um conjunto de fenômenos que afetam as sociedades que enfrentam rápidas mudanças, tais como: a insegurança econômica, o aumento do extremismo e as mudanças culturais que, por sua vez, geram ansiedade e proporcionam um terreno fértil para campanhas de desinformação que fomentam tensões sociais, polarização e desconfiança. A propagação da desinformação ocorre no contexto de um setor da comunicação social em profunda transformação, com o surgimento de plataformas ativas que tem afetado jornalistas e órgãos de comunicação social, que buscam adaptar os modelos de negócio e novas formas de rentabilizar conteúdos. O documento menciona ainda as tecnologias representadas pelas redes sociais, que, quando mal utilizadas, são manipuladas de forma a propagar a desinformação, tanto pelo mau uso dos recursos disponíveis, como mecanismos baseados em algoritmos, como no comportamento dos usuários habituados em disseminar conteúdos sem verificação prévia (COMISSÃO EUROPEIA, 2018).

Dentre as ações para combater a desinformação o Relatório da Comissão Europeia indica a promoção da educação e da Competência Infomidiática, considerando que o desenvolvimento vitalício de competências críticas e digitais, em especial para os jovens, é fator crucial para reforçar a resistência da sociedade à desinformação. O plano de ação para a 
educação digital, adotado pela Comissão em janeiro de 2018, salienta os riscos que a desinformação representa para os educadores e estudantes, e a premente necessidade de desenvolver as aptidões e competências digitais de todos os indivíduos, na educação formal e não formal. O quadro de competências digitais para os cidadãos, desenvolvido pela Comissão, apresenta o vasto conjunto de competências necessárias a todos, desde a Competência em informação, passando pela criação de conteúdos digitais, até à segurança e bem-estar nas redes (COMISSÃO EUROPEIA, 2018).

No contexto da Ciência da Informação, Pinheiro e Brito (2014) corroboram com os elementos apresentados no relatório supracitado. Os autores indicam que a falta de informação desencadeia a desinformação e a ausência de cultura ou da competência em informação impossibilita que o usuário localize e avalie por si mesmo a informação que necessita, não alcançando, portanto, suas próprias conclusões. Assim, observando os conceitos e ideias elencadas, destaca-se, dentre outras habilidades, a necessidade do uso adequado da informação, que pode ser desenvolvida por meio da apropriação dos preceitos da Competência em Informação que segundo Belluzzo (2013) deve ser reconhecida como um requisito essencial à formação básica e à formação contínua das pessoas a fim de que possam ser mais reflexivas e investigativas e consigam interagir verdadeiramente com os ambientes de expressão e construção do conhecimento.

O termo Competência em Informação é a tradução oficial adotada no Brasil para o termo em inglês Information Literacy, traduzido também em outros idiomas: o italiano Competenza Informativa, o francês - Maîtrise de I'Information, o espanhol que recebeu duas traduções: Alfabetización Informacional - ALFIN, usado na Espanha e Desarrollo de Habilidades Informativas - DHI, mais usado no México e Literacia Informacional em Portugal.

Em meados dos anos 2000, quando a temática Information Literacy começou a ser discutida no Brasil, foram várias as traduções para a expressão: Alfabetização Informacional (CAREGNATO, 2000), Letramento Informacional (CAMPELLO, 2003; GASQUE, 2006), Competência Informacional (CAMPELLO, 2002) e Competência em Informação (HATSCHBACH, 2002; BELLUZZO, 2004). Contudo, a proposição da expressão Competência em Informação como termo oficial no Brasil iniciou-se no XIII Seminário Nacional de Bibliotecas Universitárias (SNBU), realizado em Natal/RN em 2004 e consolidou-se em 2011, no Seminário "Competência em Informação: cenários e tendências", realizado durante o XXIV Congresso Brasileiro de Biblioteconomia, Documentação e Ciência da Informação em Maceió/AL sendo registrada na "Declaração de Maceió sobre a Competência em Informação", documento resultado do evento.

Em 2014, a exemplo de outros países, na "Carta de Marília" produto do "III Seminário de Competência em Informação: cenários e tendências", foi recomendada a utilização da sigla - Colnfo - para indicar essa competência, a fim de que pudesse haver diferenciação com a sigla utilizada para a Ciência da Informação (Cl). Tal decisão foi corroborada pela UNESCO, por meio da publicação Overview of Information Literacy Resources Worldwide - 1a e $2^{\text {a }}$ edições $(2013,2015)$ organizada por Horton Jr. que consolidou a utilização da expressão "Competência em Informação" como tradução oficial do termo americano Information Literacy para o português utilizado no Brasil, inclusive, estando registrada na logomarca da UNESCO para a Colnfo.

Na concepção de Paul Zurkowski, americano reconhecido como o primeiro a mencionar o termo Information Literacy em novembro de 1974, as pessoas competentes em informação são aquelas "treinadas" para aplicar os recursos informacionais em seu trabalho, pos- 
suem técnicas e habilidades para usar ferramentas e recursos primários e moldam soluções relacionadas à informação e aos seus problemas. (ZURKOWSKI, 1974, tradução nossa).

Horton Jr. (2007) indica que a Competência em Informação está intimamente aliada ao aprender a aprender e ao pensamento crítico, configurando-se como um conjunto de atitudes e conhecimentos necessários para identificar quando a informação é necessária para ajudar a resolver um problema ou tomar uma decisão; como articular essa informação precisa em termos e linguagem pesquisáveis, e buscar informações de forma eficiente, além de recuperar, interpretar, entender, organizar e avaliar a sua credibilidade e autenticidade, avaliar a sua relevância e comunicá-la aos outros. No Prefácio da 2a edição de Overview of Information Literacy Resources Worldwide (2015), o autor enfatiza que o tema em foco passou por uma rápida transição - de uma teoria abstrata no final do século XX para um lugar central no arsenal de ferramentas estratégicas do século XXI.

Os estudos contemporâneos sobre Competência em Informação estão direcionados para distintas áreas do conhecimento e configuram uma agenda de pesquisas em torno do desenvolvimento, consolidação e aplicação da Colnfo, bem como a pluralidade de novos termos e conceitos derivados da Information Literacy como: Transliteracy, Metaliteracy, Competência Midiática, Competência Digital, Competência Crítica em Informação, dentre outras. Tais pesquisas aparecem refletidas principalmente nas questões que envolvem mídia (CERIGATTO, 2018), cidadania (FARIAS; VARELA; FREIRE, 2013), educação (COSTA, 2017; FARIAS, 2014) e o universo organizacional (YAFUSHI, 2015; OTTONICAR, 2016), fatores que aproximam os indivíduos comuns à área de estudo até então restrita ao âmbito científico e acadêmico.

Essas temáticas norteiam também a promoção de eventos nacionais e internacionais e consequentemente os produtos destes eventos, que refletem recomendações, ações e estratégias, para difusão e institucionalização da Colnfo em esferas locais, regionais, nacionais e mundial: inclusão e exclusão digital e desigualdades sociais (DECLARAÇÃO DE PRAGA, 2003; MANIFESTO DE FLORIANÓPOLIS, 2013); empregabilidade e empreendedorismo (PROCLAMAÇÃO DE ALEXANDRIA, 2005); inclusão de conteúdos de Competência em Informação nos programas educativos formais e informais (DECLARAÇÃO DE LIMA, 2009; DECLARAÇÃO DE FEZ, 2011); aprendizagem ao longo da vida, pensamento crítico e outras habilidades que ultrapassam as fronteiras profissionais, educacionais e sociais (DECLARAÇÃO DE MOSCOU, 2012). Esse cenário distancia a Competência em informação do seu contexto de surgimento, restrito à biblioteca, com práticas consolidadas como a educação de usuários e orientação e instrução bibliográficas, por exemplo (DUDZIAK, 2016) e aproxima de uma perspectiva social embasada no aprendizado ao longo da vida e no pensamento crítico (DUDZIAK, 2001, 2003; HORTON JUNIOR, 2007).

As pesquisas de Vitorino e Piantola (2009), Doyle (2018), Brisola (2016) e Brisola e Romeiro (2018) em torno da temática Competência crítica em informação, ainda pouco explorada no Brasil, orientam inicialmente as reflexões em torno dos elementos apresentados nessa discussão. Doyle (2018) conceitua Competência Crítica em Informação, ainda que não seja um conceito consolidado, como sendo

[...] uma linha de estudos que critica visões, pesquisas ou projetos ideologizantes de competência em informação; integra elementos da teoria crítica da sociedade e da pedagogia crítica freiriana em suas reflexões e práticas, e se propõe a combater os efeitos do capital sobre a circulação de informação na sociedade. (DOYLE, 2018). 
Para Vitorino e Piantola (2009), a competência em informação na perspectiva crítica, abarca as habilidades para usar computadores e acessar a informação e inclui a reflexão crítica sobre a natureza, a infraestrutura técnica, o contexto e o impacto social, cultural e filosófico da informação, visando discernimento acerca do impacto causado pela informação no cotidiano. Tal proposição reflete a pertinência dos estudos em torno dos fenômenos informacionais no contexto dessa perspectiva.

Brisola e Romeiro (2018) reforçam a importância da Competência Crítica em Informação para que os indivíduos possam, além de reconhecer suas necessidades informacionais, buscar fontes seguras, acessar, analisar criticamente a informação, distinguir entre o que é relevante ou não, contextualizar, hierarquizar as informações, utilizar e produzir novas informações. Cabe a esse sujeito entender esta competência como algo adquirido ao longo da vida, que permite resistir ao cenário de desinformação e fake news, bem como se promover como um cidadão que, diante da enxurrada de informações, consegue selecionar criticamente aquelas que são importantes para si.

É nesse universo, onde o fenômeno desinformação reflete a instalação do predomínio da "pós-verdade", onde as Fake news são difundidas e consolidadas numa velocidade que incapacita inclusive a comprovação da veracidade dos fatos e a Colnfo se posiciona como uma das possibilidades de amenizar essa problemática mundial, que a Arquivologia, ciência que tem como seu objeto a informação, seja ela arquivística ${ }^{2}$, orgânica ${ }^{3}$ ou social ${ }^{4}$, necessita estabelecer relações considerando seu papel enquanto ciência, bem como o papel do arquivo e do arquivista na sociedade.

Araújo (2013) indica que é no âmbito da Arquivologia canadense que se desenvolvem importantes estudos em torno da perspectiva crítica, espaço de discussão para os elementos aqui apresentados. Terry Cook considerado o precursor dessa abordagem, inaugurou, em 1994, sob a expressão de uma "arquivologia pós-moderna", um campo de reflexões na tentativa de superar as visões positivistas calcadas em pressupostos de neutralidade e passividade. É nesse cenário que Cook (1997) indica uma "nova" visão da Arquivologia, que deveria problematizar noções como a de autoridade, evidência e verdade, causando um impacto imenso na própria prática profissional dos arquivistas, que deixariam de seguir um "script" para questionar suas ações percebendo que os arquivos e seus documentos refletem relações de poder e não são depósitos passivos e sim locais ativos onde poderes sociais são negociados, contestados e confirmados (COOK, 1997; SCHWARTZ; COOK, 2002 apud ARAÚJO, 2013).

Com relação ao profissional arquivista, Cook (2012) recomenda que esses reflitam sobre a disciplina e suas práticas e que na contemporaneidade as práticas do século XIX já não condizem com a realidade e, consequentemente, não são mais viáveis em um mundo

\footnotetext{
${ }^{2}$ A diferença da informação arquivística em relação às informações de outra natureza é que ela é produto das atividades de determinado organismo. Ou seja, ela é produzida dentro do contexto do exercício das funções/objetivos a que se propõem as entidades. Desta forma, está se tentando definir uma informação que apresenta como características básicas estar registrada em um determinado suporte e ser o resultado das ações e transações da organização (MORENO, 2007).

3 Informação elaborada, enviada ou recebida no âmbito da missão do organismo [...] a produção de informações orgânicas registradas dá origem aos arquivos do organismo. Sob esta designação, são agrupados todos os documentos, seja qual for o seu suporte e idade, produzidos e recebidos pelo organismo no exercício das suas funções (ROUSSEAU; COUTURE, 1998, p. 64-65).

${ }^{4}$ Conjunto estruturado de representações mentais codificadas (símbolos, significantes) socialmente contextualizadas e passiveis de serem registradas num qualquer suporte material (papel, filme, disco magnético, óptico, etc. e/ou comunicadas em tempos e espaços diferentes [...] sendo que o que a "coisifica" como fenômeno social é a linguagem, seus signos e significados (RIBEIRO; SILVA, 2003, p. 4).
} 
pós-moderno e informatizado. Dessa forma, o arquivista do século XXI deve ser competente para o uso de tecnologias visando excelência no desempenho de seu trabalho e precisa desenvolver habilidades para serem ativadas em qualquer situação.

Schmidt (2012) observa que o desenvolvimento dos recursos tecnológicos, bem como o surgimento de novos suportes informacionais, novos usuários, novas tecnologias de produção documental, tem provocado nos arquivistas uma reflexão sobre a prática nos arquivos, trazendo para o campo científico as ideias de "informacional" e "pós-moderno", fazendo com que a Arquivologia passe a revisar seus conceitos, funções, princípios e teorias, de modo que alguns sejam ampliados, modificados, refutados e assim surjam novas abordagens buscando resolver os desafios contemporâneos, como os fenômenos informacionais aqui apresentados.

Segundo Furtado, Belluzzo e Pazin (2016), a Arquivística contemporânea está ampliando os domínios impostos à área, buscando novos desafios teórico-metodológicos, e a aproximação com outras disciplinas, objetivando assegurar sua autonomia enquanto ciência e empreendendo relações fronteiriças com outras áreas, o que justifica inclusive o desenvolvimento da presente pesquisa, que, além de traçar relações interdisciplinares, se enquadra nos parâmetros da teoria arquivística contemporânea ou pós-custodial.

\section{PROCEDIMENTOS METODOLÓGICOS}

A presente pesquisa se consolidou em duas etapas distintas, primeiramente por meio da Pesquisa Bibliográfica, que proporcionou a sistematização dos temas de pesquisa - prioritariamente com autores da Arquivologia e Ciência da Informação, com o objetivo de construir um referencial teórico que sustente a etapa seguinte. Na segunda e principal etapa da pesquisa, desenvolveu-se uma Revisão Bibliográfica Sistemática - RBS com o intuito de identificar na literatura nacional possíveis pontos de interseção entre as temáticas Desinformação e Competência em Informação com a Arquivologia.

A RBS é um instrumento para mapear trabalhos publicados no tema de pesquisa específico para que o pesquisador seja capaz de elaborar uma síntese do conhecimento existente sobre o assunto. Uma RBS permite ao pesquisador uma avaliação rigorosa e confiável das pesquisas realizadas dentro de um tema específico. Levy e Ellis (2006) descrevem uma RBS por meio de um processo. Os autores adotam a definição de processo como "sequência de passos e atividades". Para alcançar esses resultados, Levy e Ellis (2006) definem três fases principais: Entrada; Processamento; e Saída. Na fase "entrada" estão as informações preliminares que serão processadas, por exemplo: artigos clássicos na área de estudo, livrostexto que compilam conhecimentos na área, artigos de referência indicados por especialistas. Também inclui o plano de como será conduzida a RBS, ou seja, o protocolo da RBS. Trata-se de um documento que descreve o processo, técnicas e ferramentas que serão utilizadas durante a fase 2 (processamento), que por fim irá gerar as "saídas", relatórios, síntese dos resultados. O resultado de uma RBS deve constituir o "estado da arte" e demonstrar que a pesquisa em questão contribui com algo novo para o corpo de conhecimento existente (BIOLCHINI et al., 2007, LEVY; ELLIS, 2006 apud FURTADO, 2016).

\section{PROTOCOLO E COLETA DE DADOS DA RBS: ENTRADA}

A coleta de dados para construção da presente pesquisa ocorreu na Base de Dados Referenciais de Artigos de Periódicos em Ciência da Informação (BRAPCI), escolha justificada 
pelo status que a referida base representa na Ciência da Informação. O objetivo proposto foi de localizar artigos que relacione o fenômeno e as temáticas discutidas nesta pesquisa: Desinformação, Arquivologia e Competência em Informação.

Para definição das strings ${ }^{5}$ de busca, fez-se necessária a contextualização dos termos empregados nesta pesquisa a fim de alcançar um consenso da padronização dos termos. 0 Dicionário de Terminologia Arquivística define Arquivologia como disciplina que estuda as funções do Arquivo e os princípios e técnicas a serem observados na produção, organização, guarda, preservação e utilização dos Arquivos. Também chamada Arquivística (DIBRATE, 2005).

O Tesauro Brasileiro de Ciência da Informação define Competência em Informação como conjunto de competências que uma pessoa adquire com o objetivo de identificar e localizar a informação necessária, manipular e avaliar fontes de informação, elaborar estratégias de busca e saber utilizar a informação, criando novo conhecimento e transformando-o em ação (PINHEIRO; FERRES, 2014).

O termo Competência em Informação foi oficializado no Seminário "Competência em Informação: cenários e tendências", que aconteceu no decorrer do XXIV Congresso Brasileiro de Biblioteconomia, Documentação e Ciência da Informação na cidade de Maceió/AL em 2011, e a utilização do termo foi oficializada no Brasil sendo registrada na "Declaração de Maceió sobre a Competência em Informação" (DECLARAÇÃO, 2011), documento resultante do evento e considerado como marco histórico para o Brasil. (FURTADO; BELLUZZO; PAZIN, 2016).

No Brasil, a palavra Desinformação foi identificada em busca online, realizada no Vocabulário Ortográfico da Língua Portuguesa ${ }^{6}$ (VOLP), da Academia Brasileira de Letras (ABL) e pode ser entendida como a ação de desinformar, dados falsos que induzem ao erro ou privação de conhecimento sobre determinado assunto; ignorância.

A partir dos procedimentos descritos foram estabelecidas as palavras chaves: Desinformação, Competência em Informação e Arquivologia. Na presença dos muitos sinônimos encontrados, neste trabalho optou-se em usar também Competência Informacional e Arquivística para compor as strings de busca, a fim de não tornar o trabalho repetitivo e cansativo ao leitor, buscando ênfase no objetivo estabelecido. Suas combinações resultaram no Quadro 1.

Quadro 1-strings de busca

\begin{tabular}{|l|l|}
\hline \multirow{3}{*}{ Palavras chaves PT/BR } & Strings de busca \\
\hline \multirow{3}{*}{ Arquivologística } & Arquivologia + Competência em Informação \\
\hline \multirow{3}{*}{ Competência em Informação } & Arquivística + Competência em Informação \\
\hline \multirow{3}{*}{ Competência Informacional } & Arquivologia + Competência Informacional \\
\hline \multirow{3}{*}{ Desinformação } & Arquivística + Competência Informacional \\
\hline & Arquivologística + Desinformação \\
\hline & Competência em Informação \\
\hline & Competência Informacional + Desinformação \\
\hline & Arquivologia + Competência em Informação + Desinformação \\
\hline & Arquivística + Competência em Informação + Desinformação \\
\hline & Arquivologia + Competência Informacional + Desinformação \\
\hline \multirow{2}{*}{ Fonte: Elaborado pelas autoras } & Arquivística + Competência Informacional + Desinformação \\
\hline
\end{tabular}

Fonte: Elaborado pelas autoras (2018)

\footnotetext{
${ }^{5}$ Termos combinados.

${ }^{6}$ http://www.academia.org.br/nossa-lingua/busca-no-vocabulario?sid=23.
} 
O procedimento foi realizado a fim de encontrar relações entre Desinformação e Competência em Informação no escopo da Arquivologia. A coleta de dados realizada foi em idioma Português/BR, utilizando a busca composta, no período de 1972 a 2018 . A coleta foi realizada com a página logada com os dados da pesquisadora e, na busca por termos compostos, se fez o uso das aspas duplas, conforme Figura 1.

Figura 1 - Printscreen das dez últimas strings de busca da pesquisa - BRAPCI

\begin{tabular}{|c|c|c|c|c|c|}
\hline $\begin{array}{c}\text { BRAPCI } \\
\text { Delımıtaçao }\end{array}$ & & \multirow[t]{2}{*}{ sobre índices } & \multirow[t]{2}{*}{ ferramentas $\checkmark$} & \multicolumn{2}{|c|}{ Ana Roberta Pinheiro Moura } \\
\hline Delimitação da busca: [ & $1972 \quad$ V 2018 & & & & \\
\hline \multicolumn{6}{|l|}{ historic_search } \\
\hline Data/Hora & Consulta & & & Tipo & Total \\
\hline $2 \theta 18-12-\theta 3 \quad 12: 36: 10$ & 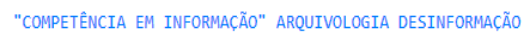 & & & todos & $\theta$ \\
\hline $2018-12-\theta 3 \quad 12: 35: 38$ & "COMPETÊNCIA EM INFoRMAC̆̃̃o" ARQUIVÍSTICA DESINForMACão & & & todos & $\theta$ \\
\hline $2018-12-\theta 3 \quad 12: 35: 2 \theta$ & "COMPETÊNCIA INFORMACIONAL" ARQUIVÍSTICA DESINFORMACÃo & & & todos & $\theta$ \\
\hline 2018-12-03 12:35:06 & "COMPETÊNCIA INFoRMACIONAL" ARQUIVOLOGIA DESINFORMACÃo & & & todos & $\theta$ \\
\hline 2018-12-03 12:34:52 & "COMPETÊNCIA INFORMACIONAL" ARQUIVOLOGIA & & & todos & 6 \\
\hline 2018-12-03 12:34:34 & "COMPETÊNCIA EM INFORMAÇ̃̃o" ARQUTVOLOGia & & & todos & 10 \\
\hline 2018-12-03 12:34:20 & "COMPETÊNCIA EM INFORMAC̆̃̃o" DESINFORMAC̄̃o & & & todos & 6 \\
\hline 2018-12-03 12:33:51 & "COMPETÊNCIA INFORMACIONAL" DESINFORMAC̄̃o & & & todos & $\theta$ \\
\hline 2018-12-83 12:33:27 & ARQUIVÍSTICA DESINFORMACÃo & & & todos & $\theta$ \\
\hline 2018-12-83 12:33:ө9 & ARQUIVOLOGIA DESINFORMAÇÃo & & & todos & $\theta$ \\
\hline
\end{tabular}

Após as buscas, foram recuperados 24 artigos, entre eles os artigos "Arquivologia e Competência em Informação: possíveis conexões por meio da abordagem a literatura internacional" e "Gestão do conhecimento e Competência em Informação: possíveis relações e perspectivas de atuação do profissional arquivista" foram resultados repetidos da string de busca: "Arquivologia + Competência em Informação" e "Arquivística + Competência em Informação".

Na sequência, foram selecionados apenas os artigos que eram pertinentes para a discussão proposta neste trabalho. A seleção foi feita por meio de leitura minuciosa buscando encontrar similaridade dos artigos com o objetivo da pesquisa, resultando num corpo de 11 artigos para análise.

\section{ANÁLISE E DISCUSSÃO DOS RESULTADOS DA RBS: PROCESSAMENTO E SAÍDA}

O processamento e a saída correspondem às duas últimas fases da RBS. O produto da coleta de dados realizada na $\mathrm{BRAPCl}$, aplicados os critérios de exclusão, resultou em um corpo composto por 11 artigos, conforme apresentado no Quadro 2. 
Quadro 2 - Resultados das buscas na base de dados da BRAPCI

(continua)

\begin{tabular}{|c|c|c|c|c|}
\hline $\begin{array}{c}\text { String } \\
\text { pesquisada }\end{array}$ & Publicação & Titulo & Autores & Palavras chaves \\
\hline \multirow{5}{*}{$\begin{array}{l}\text { Competência em } \\
\text { Informação } \quad+ \\
\text { Arquivologia }\end{array}$} & $\begin{array}{l}\text { Encontro Nacio- } \\
\text { nal de Pesquisa } \\
\text { em Ciência da } \\
\text { Informação, n. } \\
\text { XVIII ENANCIB, } \\
\text { 2017. (pt-BR) } 2\end{array}$ & $\begin{array}{l}\text { A Competência em } \\
\text { Informação na for- } \\
\text { mação em arquivolo- } \\
\text { gia. }\end{array}$ & $\begin{array}{l}\text { FURTADO, Renata } \\
\text { Lira; PAZIN, Marcia } \\
\text { Cristina Carvalho; } \\
\text { BELLUZZO, Regina } \\
\text { Célia Baptista }\end{array}$ & $\begin{array}{l}\text { Competência em } \\
\text { Informação. Colnfo. } \\
\text { Arquivologia }\end{array}$ \\
\hline & $\begin{array}{l}\text { Encontro Nacio- } \\
\text { nal de Pesquisa } \\
\text { em Ciência da } \\
\text { Informação, n. } \\
\text { XIX ENANCIB, } \\
\text { 2018. (pt-BR) } 2\end{array}$ & $\begin{array}{l}\text { Arquivologia e Com- } \\
\text { petência em Infor- } \\
\text { mação: Possíveis } \\
\text { conexões por meio } \\
\text { da abordagem à } \\
\text { literatura internacio- } \\
\text { nal }\end{array}$ & $\begin{array}{l}\text { FURTADO, Renata } \\
\text { Lira; BELLUZZO, } \\
\text { Regina Célia Baptis- } \\
\text { ta; VITORIANO, } \\
\text { Marcia Cristina de } \\
\text { Carvalho Pazin }\end{array}$ & $\begin{array}{l}\text { Arquivologia. Compe- } \\
\text { tência em Informa- } \\
\text { ção. Revisão Sistemá- } \\
\text { tica Bibliográfica. }\end{array}$ \\
\hline & $\begin{array}{l}\text { Em Questão, n. 3, } \\
\text { v. 23, 2017. (pt- } \\
\text { BR) } 2 \text { Informação } \\
\text { \& Informação, n. } \\
2 \text {, v. } 23,2018 \text {. (pt- } \\
\text { BR) } 2\end{array}$ & $\begin{array}{l}\text { Diálogo entre as } \\
\text { dimensões da Com- } \\
\text { petência em Infor- } \\
\text { mação e os cursos de } \\
\text { graduação em Arqui- } \\
\text { vologia do sul do } \\
\text { Brasil }\end{array}$ & $\begin{array}{l}\text { MARTENDAL, Fer- } \\
\text { nanda Frasson; } \\
\text { SILVA, Eva Cristina } \\
\text { Leite da; VITORINO, } \\
\text { Elizete Vieira }\end{array}$ & $\begin{array}{l}\text { Ciência da Informa- } \\
\text { ção. Arquivologia. } \\
\text { Gestão da Informa- } \\
\text { ção e do Conheci- } \\
\text { mento. Arquivista. } \\
\text { Gestão do Conheci- } \\
\text { mento. Competência } \\
\text { em Informação. }\end{array}$ \\
\hline & $\begin{array}{l}\text { Ágora, n. 49, v. } \\
24,2014 . \text { (pt-BR) } \\
2\end{array}$ & $\begin{array}{l}\text { Emprego das compe- } \\
\text { tências em informa- } \\
\text { ção pelos estudantes } \\
\text { de Arquivologia da } \\
\text { universidade federal } \\
\text { da Bahia }\end{array}$ & $\begin{array}{l}\text { BRANDÃO, Gleise } \\
\text { da Silva; LIMA, } \\
\text { Jussara Borges de }\end{array}$ & $\begin{array}{l}\text { Ciência da Informa- } \\
\text { ção. Arquivologia. } \\
\text { Competência em } \\
\text { Informação. Processo } \\
\text { Cognitivo. Estudante } \\
\text { de Arquivologia- } \\
\text { UFBA. Competência } \\
\text { em Informação do } \\
\text { Estudante de Arqui- } \\
\text { vologia da UFBA. }\end{array}$ \\
\hline & $\begin{array}{l}\text { Informação } \quad \text { \& } \\
\text { Informação, n. 2, } \\
\text { v. 23, 2018. (pt- } \\
\text { BR) 2 }\end{array}$ & $\begin{array}{l}\text { Gestão do conheci- } \\
\text { mento e Competên- } \\
\text { cia em Informação: } \\
\text { possíveis relações e } \\
\text { perspectivas de atua- } \\
\text { ção do profissional } \\
\text { arquivista }\end{array}$ & $\begin{array}{l}\text { FURTADO, Renata } \\
\text { Lira; BELLUZZO, } \\
\text { Regina Celia Baptis- } \\
\text { ta }\end{array}$ & $\begin{array}{l}\text { Arquivista. Gestão do } \\
\text { Conhecimento. Com- } \\
\text { petência em Infor- } \\
\text { mação. }\end{array}$ \\
\hline \multirow{2}{*}{$\begin{array}{l}\text { Competência em } \\
\text { Informação }+ \\
\text { Desinformação. }\end{array}$} & $\begin{array}{l}\text { Liinc em revista, } \\
\text { n. 2, v. 13, } 2017 . \\
\text { (pt-BR) } 2\end{array}$ & $\begin{array}{l}\text { Competência em } \\
\text { Informação e Desin- } \\
\text { formação: critérios } \\
\text { de avaliação do con- } \\
\text { teúdo das fontes de } \\
\text { informação }\end{array}$ & ZATTAR, Marianna & $\begin{array}{l}\text { Competência em } \\
\text { Informação; Fontes } \\
\text { de Informação; De- } \\
\text { sinformação }\end{array}$ \\
\hline & $\begin{array}{l}\text { Encontro Nacio- } \\
\text { nal de Pesquisa } \\
\text { em Ciência da } \\
\text { Informação, n. } \\
\text { XIX ENANCIB, } \\
\text { 2018. (pt-BR) } 2\end{array}$ & $\begin{array}{l}\text { Contribuição da teo- } \\
\text { ria crítica aos estudos } \\
\text { sobre regime de } \\
\text { informação e compe- } \\
\text { tência crítica em } \\
\text { informação }\end{array}$ & $\begin{array}{l}\text { BEZERRA, } \\
\text { Coelho }\end{array}$ & $\begin{array}{l}\text { Teoria Crítica. Regi- } \\
\text { me de Informação. } \\
\text { Competência em } \\
\text { Informação. Compe- } \\
\text { tência Crítica em } \\
\text { Informação. Desin- } \\
\text { formação. }\end{array}$ \\
\hline
\end{tabular}

Fonte: elaborado pelas autoras (2018). 
Quadro 2 - Resultados das buscas na base de dados da BRAPCI

(continuação)

\begin{tabular}{|c|c|c|c|c|}
\hline $\begin{array}{c}\text { String } \\
\text { pesquisada }\end{array}$ & Publicação & Titulo & Autores & Palavras chaves \\
\hline \multirow{2}{*}{$\begin{array}{l}\text { Competência em } \\
\text { Informação }+ \\
\text { Desinformação. }\end{array}$} & $\begin{array}{l}\text { Revista Brasileira } \\
\text { de Bibliotecono- } \\
\text { mia e Documen- } \\
\text { tação, n. 3, v. 14, } \\
\text { 2018. (pt-BR) } 2\end{array}$ & $\begin{array}{l}\text { A competência crítica } \\
\text { em informação como } \\
\text { resistência: uma } \\
\text { análise sobre o uso } \\
\text { da informação na } \\
\text { atualidade }\end{array}$ & $\begin{array}{l}\text { BRISOLA, Anna } \\
\text { Cristina; ROMEIRO, } \\
\text { Nathália Lima }\end{array}$ & $\begin{array}{l}\text { Competência Crítica } \\
\text { em Informação. Éti- } \\
\text { ca. Cidadania. Desin- } \\
\text { formação. Compe- } \\
\text { tência em Informa- } \\
\text { ção }\end{array}$ \\
\hline & $\begin{array}{l}\text { Encontro Nacio- } \\
\text { nal de Pesquisa } \\
\text { em Ciência da } \\
\text { Informação, n. } \\
\text { XIX ENANCIB, } \\
\text { 2018. (pt-BR) } 2\end{array}$ & $\begin{array}{l}\text { Desinformação e } \\
\text { circulação de "fake } \\
\text { news": distinções, } \\
\text { diagnóstico e reação }\end{array}$ & $\begin{array}{l}\text { BRISOLA, Anna; } \\
\text { BEZERRA, Arthur } \\
\text { Coelho }\end{array}$ & $\begin{array}{l}\text { Desinformação. Fake } \\
\text { News. Competência } \\
\text { Crítica em Informa- } \\
\text { ção. Competência em } \\
\text { Informação }\end{array}$ \\
\hline \multirow{2}{*}{$\begin{array}{l}\text { Arquivologia } \\
\text { competência } \\
\text { Informacional }\end{array}$} & $\begin{array}{l}\text { Em Questão, n. 2, } \\
\text { v. 20, 2014. (pt- } \\
\text { BR) } 2\end{array}$ & $\begin{array}{l}\text { A competência in- } \\
\text { formacional funda- } \\
\text { mentada na dimen- } \\
\text { são ética }\end{array}$ & $\begin{array}{l}\text { MENEZES, Priscila } \\
\text { Lopes; VITORINO, } \\
\text { Elizete Vieira }\end{array}$ & $\begin{array}{l}\text { Ciência da Informa- } \\
\text { ção. Arquivologia. } \\
\text { Biblioteconomia. } \\
\text { Competência Infor- } \\
\text { macional. Ética. Pro- } \\
\text { fissional da Informa- } \\
\text { ção. Atitude. Virtude. }\end{array}$ \\
\hline & $\begin{array}{l}\text { Revista Brasileira } \\
\text { de Educação em } \\
\text { Ciência da Infor- } \\
\text { mação, n. 1, v. 1, } \\
\text { 2014. (pt-BR) } 2\end{array}$ & $\begin{array}{l}\text { Práticas de pesquisa } \\
\text { de estudantes de } \\
\text { biblioteconomia e } \\
\text { arquivologia: uma } \\
\text { abordagem sobre os } \\
\text { aspectos afetivos } \\
\text { envolvidos e a com- } \\
\text { petência informacio- } \\
\text { nal }\end{array}$ & $\begin{array}{l}\text { GONÇALVES, Rena- } \\
\text { ta Braz; GODINHO, } \\
\text { Natalia Bermudez }\end{array}$ & $\begin{array}{l}\text { Competência Infor- } \\
\text { macional. Curso de } \\
\text { Biblioteconomia. } \\
\text { Curso de Arquivolo- } \\
\text { gia. Ciência da Infor- } \\
\text { mação. Prática de } \\
\text { Pesquisa. }\end{array}$ \\
\hline
\end{tabular}

Fonte: elaborado pelas autoras (2018).

Apresentados os resultados das buscas, o conjunto de 11 artigos e considerando a facilidade de análise pela sua totalidade baixa, optou-se por realizar a leitura completa de cada um dos artigos, apresentar análises individuais e na sequência apontar os resultados encontrados. Para organizar a apresentação e discussão, os artigos foram numerados conforme segue.

O Artigo 1 "A Competência em Informação na formação em Arquivologia" é de autoria de Renata Lira Furtado, Marcia Cristina Carvalho Pazin e Regina Célia Baptista Belluzzo, apresentado no Encontro Nacional de Pesquisa em Ciência da Informação - XVIII ENANCIB, 2017. O trabalho é resultado da investigação, realizada com o propósito de identificar a inserção da temática Competência em Informação nos cursos de graduação em Arquivologia no Brasil, levando em consideração que pesquisas envolvendo a temática ainda são insipientes no âmbito nacional em relação as pesquisas realizadas em âmbito internacional, concluindo que a pesquisa mostrou grande relevância evidenciando que Competência em Informação está presente nos documentos norteadores da formação arquivística mesmo que de forma implícita (FURTADO; PAZIN; BELLUZZO, 2017). 
O Artigo 2 "Arquivologia e Competência em Informação: possíveis conexões por meio da abordagem à literatura internacional" de autoria de Renata Lira Furtado, Regina Célia Baptista Belluzzo e Marcia Cristina de Carvalho Pazin Vitoriano, apresentado no Encontro Nacional de Pesquisa em Ciência da Informação - XIX ENANCIB, 2018. O trabalho é resultado da pesquisa que objetiva identificar a presença da Competência em Informação na literatura arquivística internacional, por meio de uma Revisão Bibliográfica Sistemática, pautada nos idiomas inglês, francês e espanhol, que resultou em quatro artigos no idioma inglês. $A$ análise desses artigos culminou na descoberta dos termos "Archival Literacy" e "Archival Intelligence" que ampliam o leque teórico em torno da discussão estabelecida entre a díade Arquivologia e Competência em Informação (FURTADO; PAZIN; BELLUZZO, 2018).

O Artigo 3 “Diálogo entre as dimensões da Competência em Informação e os cursos de graduação em Arquivologia do sul do Brasil" é de autoria de Fernanda Frasson Martendal, Eva Cristina Leite da Silva e Elizete Vieira Vitorino e foi publicado pela revista Em Questão no ano de 2017. O estudo é produto da pesquisa que buscou identificar as quatro dimensões (ética, política, estética e técnica) da Competência em Informação nos egressos dos cursos de Arquivologia de três universidades do sul do Brasil, considerando que a presença destas dimensões auxilia o desenvolvimento do profissional arquivista. $O$ artigo conclui que as quatro dimensões estão presentes nos referidos cursos de graduação, considerando principalmente a relação interdisciplinar oriunda entre Arquivologia e Ciência da Informação (MARTENDAL; SILVA; VITORINO, 2017).

O Artigo 4 "Emprego das competências em informação pelos estudantes de Arquivologia da Universidade Federal da Bahia" é de autoria de Gleise da Silva Brandão e Jussara Borges de Lima, publicado pela Ágora em 2014. O objetivo da pesquisa é verificar o emprego da Competência em Informação pelos estudantes ingressantes e concluintes do Curso de Arquivologia da Universidade Federal da Bahia (UFBA). A construção teórica do artigo discute, dentre outras questões, o papel da Colnfo na formação do profissional arquivista contemporâneo que irá se deparar em seu ambiente de trabalho, com a necessidade informacional dos usuários, imersos em uma sociedade cada vez mais alicerçada na informação. As autoras embasam essa discussão na Arquivologia pós-custodial centrada na informação, universo esse, em que o arquivista precisa se adequar para atender às demandas do mercado de trabalho, da sociedade e da comunidade científica, o que evidencia a necessidade do desenvolvimento da Colnfo, para que esse profissional, dentre outras habilidades, saiba buscar, acessar, avaliar, produzir e usar as informações, bem como interagir com os recursos informacionais e digitais (BRANDÃO; BORGES, 2014).

O Artigo 5 "Gestão do Conhecimento e Competência em Informação: possíveis relações e perspectivas de atuação do profissional arquivista" é de autoria de Renata Lira Furtado e Regina Celia Baptista Belluzzo, publicado por Informação \& Informação, 2018. O objetivo do artigo foi estabelecer uma relação entre o papel do arquivista na sociedade contemporânea, envolvendo sua atuação no contexto da Gestão do Conhecimento e no desenvolvimento da Competência em Informação. Os resultados indicam que é possível a atuação do arquivista na Gestão do Conhecimento, considerando os preceitos teóricos da Arquivologia pós-custodial e a relevância do desenvolvimento da Competência em Informação para atuação profissional nesse cenário, diante da identificação das necessidades de conversão do conhecimento tácito em explícito e na atuação em ações de promoção da Competência em Informação para os sujeitos da organização. Por fim, as autoras refletem sobre a atuação prática do arquivista na Gestão do Conhecimento e na Competência em Informação, que remete para outra situação: questionar se os profissionais arquivistas atuantes estão prepa- 
rados para essa realidade pós-custodial, ou ainda enfrentam uma realidade de arquivos como depósitos de documentos, da arquivística empírica, pautada no senso comum, de desvalorização do profissional e se os cursos de graduação em Arquivologia propiciam esse tipo de reflexão, de experiência (FURTADO; BELLUZZO, 2018).

O Artigo 6 "Competência em Informação e Desinformação: critérios de avaliação do conteúdo das fontes de informação" de autoria de Marianna Zattar, publicado por Liinc em revista em 2017. Apresenta as principais estratégias para avaliação dos conteúdos das fontes de informação utilizando a noção de Competência em Informação, Fontes de informação e Desinformação ao desenvolvimento das tecnologias de informação e comunicação e, especialmente, à internet e à web, que possibilitem a participação de múltiplos atores na produção e no uso de informações. A autora conclui que indicação de três critérios para avaliação de fontes de informação para que sejam evitados os compartilhamentos e usos de desinformações (e seus respectivos impactos negativos) na prática informacional. Por fim, evidencia que a necessidade de avaliação é essencial para a solidariedade na produção e para o uso crítico e ético da informação. (ZATTAR, 2017).

O Artigo 7 "Contribuição da teoria crítica aos estudos sobre regime de informação e competência crítica em informação." de autoria de Arthur Coelho Bezerra, apresentado no Encontro Nacional de Pesquisa em Ciência da Informação - XIX ENANCIB, 2018. O estudo objetiva apontar as possíveis contribuições da teoria crítica, de matriz filosófica e sociológica, para a reflexão dos estudos informacionais em torno dos dois conceitos mencionados regime de informação e competência crítica em informação. O percurso metodológico para alcançar tal objetivo se inicia com uma breve abordagem dos fundamentos da teoria crítica. Em um segundo momento, o conceito de regime de informação é apresentado como ferramenta para se pensar, à luz da teoria crítica, as tensões e contradições do ecossistema informacional da atualidade. Alcançado tal resultado, chega-se ao conceito de competência crítica em informação sob a ótica de uma práxis transformadora, procurando extrair da relação dialética entre teoria e prática as condições de produção de novas formas sociais de vida (BEZERRA, 2018).

O Artigo 8 "A competência crítica em informação como resistência: uma análise sobre o uso da informação na atualidade." de autoria de Anna Cristina Brisola e Nathália Lima Romeiro publicado na Revista Brasileira de Biblioteconomia e Documentação em 2018, discute sobre as relações entre a informação e a cidadania a partir de perspectivas da Ética e da Competência Crítica em Informação e reforça a relevância da Competência Crítica em Informação e do papel de profissionais de Biblioteconomia no aprimoramento desta crítica e competência, para resistir a desinformação, fake news e boatos, bem como promover um cidadão que, diante da enxurrada de informações, consiga selecionar criticamente aquelas que são importantes para si (BRISOLA; ROMEIRO, 2018).

O Artigo 9 “Desinformação e circulação de 'fake news': distinções, diagnóstico e reação," de autoria de Anna Brisola e Arthur Coelho Bezerra, apresentado no Encontro Nacional de Pesquisa em Ciência da Informação - XIX ENANCIB, 2018. A pesquisa busca distinguir os conceitos de Desinformação e fake news, reconhecendo tanto a sua existência prévia ao advento das redes digitais como a sua reconfiguração no ambiente online, o artigo destaca como estes fenômenos podem afetar a democracia e alerta para a possibilidade do combate às fake news resvalar para a criação de mecanismos de censura. Os autores apontam como um possível caminho para a reação a esses problemas o desenvolvimento de habilidades como a avaliação crítica e o uso ético da informação, práticas contempladas pelo conceito de competência crítica em informação (critical information literacy) e entendem que tal compe- 
tência prepara as pessoas para analisar criticamente as informações e permite-lhes usá-las para produzir novos conhecimentos de forma criativa e contextualizada (BRISOLA; BEZERRA, 2018).

O Artigo 10 "A competência informacional fundamentada na dimensão ética" de autoria de Priscila Lopes Menezes e Elizete Vieira Vitorino, publicado no periódico Em Questão em 2014, expõe atitudes e virtudes tidas como básicas, que fundamentam a conduta dos profissionais da informação, tendo seu foco na dimensão ética da Competência em Informação, entendendo que os profissionais da informação, desde a sua formação, são orientados a atuar com proficiência e dinâmica nas atividades profissionais. Tais habilidades tornam-se essenciais dentro das organizações e sustentam suas atividades num tripé que leva em conta os conhecimentos, as habilidades e as atitudes, componentes que resultam na Competência em Informação. Concluem que o papel dos profissionais da informação não se encerra no ato de disponibilizar a informação (MENEZES; VITORINO, 2014).

O Artigo 11 "Práticas de pesquisa de estudantes de Biblioteconomia e Arquivologia: uma abordagem sobre os aspectos afetivos envolvidos e a competência informacional" de autoria de Renata Braz Gonçalves e Natalia Bermudez Godinho publicado por Revista Brasileira de Educação em Ciência da Informação, 2014. A pesquisa averigua o enfoque da Competência em Informação, como estudantes universitários do 30 ano dos cursos de graduação Arquivologia e Biblioteconomia da FURG, efetuam suas buscas informacionais para pesquisas acadêmicas, considerando que o profissional da área de Arquivologia terá atribuições que predominam tarefas como identificação, classificação, ordenação, valoração, seleção, eliminação, expurgo, descrição e armazenamento de documentos. Concluindo que ocorrem falhas na formação escolar anterior à universidade que diz respeito ao ensino de práticas de pesquisas (GONÇALVES; GODINHO, 2014).

Em síntese, os artigos de 1 a 11 pertencem ao universo de resultados do procedimento de coleta realizada na $\mathrm{BRAPCl}$, que visou mapear possíveis interseções entre o fenômeno Desinformação e as temáticas Competência em Informação e Arquivologia por meio da RBS.

Os artigos de 1 a 5 foram recuperados com a string de busca "Competência em Informação + Arquivologia" e as temáticas abrangem questões relativas à presença da Colnfo na literatura arquivística em âmbito internacional e nos cursos de formação em Arquivologia, bem como a relação dos estudantes de Arquivologia com a temática e a importância da Colnfo na atuação profissional do arquivista.

Por meio desse resultado, foi possível observar que as pesquisas que relacionam a Arquivologia e a Competência em Informação ainda são insipientes, mas ganham força no atual contexto, considerando que as discussões em torno dessa relação já acontecem internacionalmente, enquanto que no Brasil, as poucas pesquisas realizadas já revelam a presença da Competência em Informação nas grades curriculares dos cursos de graduação em Arquivologia. A inserção da Colnfo na formação do arquivista, bem como nas atividades desenvolvidas no cenário contemporâneo, se faz necessária considerando principalmente, sua atuação no rol dos profissionais da informação, que necessitam de habilidades e atitudes específicas à sua atuação profissional.

Ainda nesse contexto, os artigos 10 e 11 foram recuperados pela string de busca "Competência Informacional + Arquivologia" e apresentam discussões voltadas aos estudantes de graduação em Arquivologia, investigando como e se há desenvolvimento da Competência em Informação e de que forma a mesma é aplicada.

Os artigos de 6 a 9 foram resultados da string de busca "Competência em Informação + Desinformação" e abarcam estudos sobre o fenômeno Desinformação bem como a aplica- 
bilidade das habilidades desenvolvidas através da Competência em Informação como forma de reduzir os impactos das notícias falsas disseminadas principalmente na internet. $O$ uso das habilidades e atitudes obtidos por meio da aplicação da Competência em Informação está diretamente associado à cidadania e a perspectiva ética, dessa forma se presume que a inclusão desse tema na formação de profissionais de informação seja um grande passo para mudar o exercício destes profissionais, não só em seus ambientes de trabalho como também na sua visão de mundo e participação na mudança social de diferentes comunidades.

Para as strings de busca que fazem alusão a possíveis interseções entre Arquivologia, Competência em Informação e Desinformação, não foi recuperado nenhum artigo, evidenciando uma lacuna a ser explorada pela ciência arquivística no Brasil. Acredita-se na pertinência dessa discussão considerando uma série de fatores tais como: estar a desinformação associada diretamente às novas tecnologias de informação e comunicação, o que impacta diretamente na produção, no gerenciamento e na disseminação da informação arquivística, o que remete a elementos que interferem na qualidade dessa informação como confiabilidade e autenticidade, por exemplo.

Outro fator relevante que vale ser considerado nesta seara envolve o acesso à informação ou à desinformação, que por sua vez remete às práticas informacionais críticas e éticas, envolvendo produtor da informação, usuário e arquivista, que necessitam estar alinhados com as habilidades preconizadas pela competência em informação. Além dessas questões extremamente relevantes encontra-se o universo teórico, que propicia, por exemplo, uma ampla discussão aliando as teorias já consolidadas, com percepções ainda em desenvolvimento como a noção de verdade e autenticidade de Cook (2012) e Duranti et al. (2017) que também têm se debruçado sobre as questões em torno da pós verdade e da desinformação no universo arquivístico, temáticas abordadas também por Lemieux e Smith (2018).

\section{CONSIDERAÇÕES FINAIS}

Ao finalizar este estudo que objetivou identificar possíveis interseções entre a Competência em Informação e a Desinformação no contexto arquivístico, foi possível observar a inexistência de produção acadêmico-científica com essa abordagem. Identificou-se uma produção ainda que escassa no que diz respeito à Competência em Informação e a Arquivologia, sendo que, em relação ao fenômeno Desinformação, ficou evidente que a produção em torno dessa temática nesse contexto, se mantém atrelada à Ciência da Informação.

Cabe ressaltar que os resultados desta pesquisa se caracterizam como um ensaio inicial para pesquisas futuras, configurando, contudo, como um contributo significativo tanto para a Arquivologia e Ciência da Informação como para a sociedade em geral, considerando que o fenômeno desinformação ainda é pouco compreendido e vem de maneira genérica assolando a sociedade. No contexto arquivístico, a disseminação e a preservação de fake news, por exemplo, além de outras formas de desinformação, poderão acarretar danos irreparáveis para a sociedade futura.

Esses resultados foram relevantes para confirmar que os preceitos da Competência em Informação na perspectiva crítica configuram-se como uma possibilidade tanto de combate, como de redução da desinformação na sociedade, fatores que estimulam a continuidade de pesquisas nesta seara com perspectivas de expansão para as discussões em torno dos fenômenos informacionais aqui abordados e outros que, por ventura, venham assolar a sociedade e impactar o cenário arquivístico, além de investigações em torno da formação e atuação do arquivista nesse contexto. 


\section{REFERÊNCIAS}

ARAÚJO, C. A. Á. Correntes teóricas da Arquivologia. Encontros Bibli: revista eletrônica de biblioteconomia e Ciência da Informação, v. 18, n. 37, p. 61-82, 2013. Disponível em: https://periodicos.ufsc.br/index.php/eb/article/view/28215. Acesso em: 18 set 2018

ARQUIVO NACIONAL. Dicionário Brasileiro de Terminologia Arquivística. Rio de Janeiro: Arquivo Nacional, 2005.

BARRETO, A. A. A questão da informação. São Paulo em perspectiva, v. 8, n. 4, p. 3-8, 1994. Disponível em:

http://bogliolo.eci.ufmg.br/downloads/BARRETO\%20A\%20Questao\%20da\%20Informacao.p df. Acesso em: 20 dez. 2018.

BELLUZZO, R. C. B.; KERBAUY, M. T. M. Em busca de parâmetros de avaliação da formação contínua de professores do ensino fundamental para o desenvolvimento da Information Literacy. Educação Temática Digital, v. 5, n. 2, p. 129-139, jun. 2004. Disponível em: https://periodicos.sbu.unicamp.br/ojs/index.php/etd/article/view/766/781. Acesso em: 20 dez. 2018.

BELLUZZO, R. C. B. Competência em Informação (Colnfo) e midiática: inter-relação com a Agenda 2030 e os Objetivos de Desenvolvimento Sustentável (ODS) sob a ótica da educação contemporânea. Pesquisa Brasileira em Ciência da Informação e Biblioteconomia, v. 13, n. 2, 2018. Disponível em: http://www.periodicos.ufpb.br/index.php/pbcib/article/view/43366. Acesso em: 15 ago. 2018.

BELLUZZO, R. C. B. Competência em Informação: vivências e aprendizado. In: BELLUZZO, R. C. B.; FERES, G. G. (Org.) Competência em Informação: das reflexões às lições aprendidas. São Paulo: FEBAB, v. 1, p. 58-74, 2013. Disponível em: https://labirintodosaber.com.br/wpcontent/uploads/2017/12/compete\%CC\%82ncia-em-informac\%CC\%A7a\%CC\%83o-dereflexo\%CC\%83es-a\%CC\%80s-lic\%CC\%A70\%CC\%83es-aprendidas1.pdf. Acesso em: 14 ago. 2018.

BEZERRA, A. C. Contribuição da Teoria Crítica aos estudos sobre regime de informação e competência crítica em informação. In: ENCONTRO NACIONAL DE PESQUISA EM CIÊNCIA DA INFORMAÇÃO, 19., 2018, Londrina. Anais... Londrina: UEL, 2018. Disponível em: http://enancib.marilia.unesp.br/index.php/XIXENANCIB/xixenancib/paper/view/1354. Acesso em: 10 nov. 2018.

BIOLCHINI, J.; MIAN, P. G.; NATALI, A. C. C.; TRAVASSOS, G. H. Systematic review in software engineering. Technical Report. Systems Engineering and Computer Science Department. COPPE/UFRJ, Rio de Janeiro, 2005. Disponível em: http://disciplinas.stoa.usp.br/pluginfile.php/92788/course/section/27982/Biolchini2005 Sys tematic Review in Software Engineering.pdf. Acesso em: 1 set. 2018. 
BRANDÃO, G. S.; BORGES, J. Emprego das competências em informação pelos estudantes de Arquivologia da Universidade Federal da Bahia. Ágora, v. 24, n. 49, p. 277-310, 2014. Disponível em: https://agora.emnuvens.com.br/ra/article/view/512. Acesso em: 18 ago. 2018.

BRISOLA, A. C.; ROMEIRO, N. L. A competência crítica em informação como resistência: uma análise sobre o uso da informação na atualidade. RBBD. Revista Brasileira de Biblioteconomia e Documentação, v. 14, n. 3, p. 68-87, 2018. Disponível em:

https://rbbd.febab.org.br/rbbd/article/view/1054. Acesso em: 11 nov. 2018.

BRISOLA, A. C. C. A. S. A ágora digital, a competência crítica em informação e a cidadania ampliada: uma construção possível. 146f., 2016. Dissertação (Mestrado em Ciência da Informação) - Escola de Comunicação, Universidade Federal do Rio de Janeiro, Instituto Brasileiro de Informação em Ciência e Tecnologia, Rio de Janeiro, 2016. Disponível em: http://ridi.ibict.br/handle/123456789/890. Acesso em: 1 fev. 2019.

BRISOLA, A.; BEZERRA, A. C. Desinformação e circulação de "fake news": distinções, diagnóstico e reação. In: ENCONTRO NACIONAL DE PESQUISA EM CIÊNCIA DA INFORMAÇÃO, 19., 2018, Londrina. Anais... Londrina: UEL, 2018. Disponível em:

http://enancib.marilia.unesp.br/index.php/XIXENANCIB/xixenancib/paper/view/1219. Acesso em: 10 nov. 2018.

CAMPELLO, B. A competência informacional na educação para o século XXI. In: CAMPELLO, B. (Org.) A biblioteca escolar: temas para uma prática pedagógica. Belo Horizonte: Autêntica: 2012. v. 2, p. 9-11.

CAMPELLO, B. O movimento da competência informacional: uma perspectiva para o letramento informacional. Ciência da informação, Brasília, v. 32, n. 3, p. 28-37, set./dez. 2003. Disponível em: http://revista.ibict.br/ciinf/article/view/986/1027. Acesso em: 10 nov. 2018.

CERIGATTO, M. P. Diálogos possíveis entre competências informacional e midiática: revisão da literatura e posicionamento de instituições da área. 2018. Disponível Em https://repositorio.unesp.br/bitstream/handle/11449/153455/cerigatto $\mathrm{mp} \mathrm{dr}$ mar.pdf?se quence=3\&isAllowed=y. Acesso em: 12 out. 2018.

COMISSÃO EUROPEIA. Combater a desinformação em linha: uma estratégia europeia. Bruxelas: Comissão Européia, 2018. Disponível em: https://eur-lex.europa.eu/legalcontent/PT/TXT/?uri=CELEX\%3A52018DC0236. Acesso em: 02 nov. 2018.

COOK, D. J., MULROW, C. D.; HAYNES, B. R. Systematic reviews: synthesis of best evidence for clinical decisions. Annals of Internal Medicine, v.126, n.5, pp.376-380, 1997. Disponível em: https://annals.org/aim/article-abstract/710356. Acesso em: 11 ago. 2018.

COOK, T. Arquivologia e pós-modernismo: novas formulações para velhos conceitos. Informação arquivística, Rio de Janeiro, v. 1, n. 1, 2012. Disponível em:

http://www.aaerj.org.br/ojs/index.php/informacaoarquivistica/article/view/9. Acesso em: 4 ago. 2018. 
COSTA, C. R. A Competência em Informação (Coinfo) na perspectiva da educação inclusiva. 2017. Tese (Doutorado em Ciência da Informação) - Faculdade de Ciência da Informação, Universidade de Brasília, Brasília, DF, 2017. Disponível em:

https://core.ac.uk/download/pdf/94141258.pdf. Acesso em: 14 dez. 2018.

DECLARACIÓN DE FEZ. In: FÓRUM INTERNACIONAL DE SOBRE ALFABETIZACIÓN INFORMACIONAL Y MIDIÁTICA, 2011, Marrocos: UNESCO, 2011. Disponível em: http://www.unesco.org/new/fileadmin/MULTIMEDIA/HQ/Cl/Cl/pdf/news/Fez\%20Declaratio n.pdf. Acesso em: 14 ago. 2018.

DECLARACIÓN DE LIMA. In: Taller de alfabetización informacional: formando a los formadores. 2009, Lima: UNESCO, 2009. Disponível em: http://www.pucp.edu.pe/error/\#inicio. Acesso em: 14 ago. 2018.

DECLARAÇÃO DE MOSCOU. Sobre Alfabetização Informacional e Midiática. 2012. Disponível em: http://ifapcom.ru/files/News/Images/2012/mil/Moscow Declaration on MIL eng.pdf. Acesso em: 22 jan 2019.

DIBRATE, DICIONÁRIO BRASILEIRO DE TERMINOLOGIA ARQUIVÍSTICA. Rio de Janeiro: Arquivo Nacional, 2005. Publicações Técnicas, v. 51, p. 175-178, 2013.

DOYLE, A. Ideologia e Competência Crítica em Informação: um olhar para movimentos de biblioteconomia crítica. Folha de Rosto, v. 4, n. 1, p. 25-33, 2018.Disponível em: https://periodicos.ufca.edu.br/ojs/index.php/folhaderosto/article/view/274. Acesso em: 13 fev. 2019

DUDZIAK, E. A. A information literacy e o papel educacional das bibliotecas. São Paulo, 2001. Dissertação (Mestrado em Ciência da Comunicação) - Universidade de São Paulo, São Paulo, 2001. Disponível em: http://www.teses.usp.br/teses/disponiveis/27/27143/tde30112004-151029/. Acesso em: 21 jun. 2018.

DUDZIAK, E. A. Information literacy: princípios, filosofia e prática. Ciência da Informação, Brasília, v. 32, n.1, p. 23-25, jan./abr. 2003. Disponível em:

http://revista.ibict.br/ciinf/index.php/ciinf/article/view/123. Acesso em: 20 jun. 2018.

DURANTI, L.; HOFMAN, D.; HOW, E. Trust in the Balance: Data Protection Laws as Tools for Privacy and Security in the Cloud. Algorithms, v. 10, n. 2, p. 47, 2017. Disponível em: https://www.mdpi.com/1999-4893/10/2/47. Acesso em: 14 set. 2018.

FARIAS, L. L. S. Inserção da competência em informação nos cursos de graduação em Arquivologia. Trabalho de Conclusão de Curso (Graduação em arquivologia) - Faculdade de Arquivologia, Universidade Federal do Pará. Belém, p. 36. 2018. Disponível em: http://bdm.ufpa.br/jspui/handle/prefix/628. Acesso em 9 ago. 2018.

FARIAS, M. G. G.; VARELA, A. V.; FREIRE, I. M. Ações de informação de caráter relacional e formativo para intervenção em uma comunidade urbana. In: ENCONTRO NACIONAL DE PESQUISA EM CIÊNCIA DA INFORMAÇÃO, 13., Florianópolis: UFSC, 2013. Anais eletrônicos... Florianópolis: UFSC, 2013. Disponível em: 
http://repositorio.ufc.br/bitstream/riufc/17766/1/2013 eve mggfarias.pdf. Acesso em: 25 nov. 2018.

FEDERAÇÃO BRASILEIRA DE ASSOCIAÇÕES DE BIBLIOTECÁRIOS, CIENTISTAS DA INFORMAÇÃO E INSTITUIÇÕES. Declaração de Maceió sobre a Competência em Informação. In: CONGRESSO BRASILEIRO DE BIBLIOTECONOMIA, DOCUMENTAÇÃO E CIÊNCIA DA INFORMAÇÃO, 24. 2011, Maceió. Anais eletrônicos... Maceió: FEBAB, IBICT, UnB. 2011. Disponível em: http://www.cfb.org.br/UserFiles/File/Declaracao\%20de\%20Maceio\%20sobre\%20Competen cia\%20em\%20Informacao.pdf. Acesso em: 28 set. 2018.

FEDERAÇÃO BRASILEIRA DE ASSOCIAÇÕES DE BIBLIOTECÁRIOS, CIENTISTAS DA INFORMAÇÃO E INSTITUIÇÕES. Manifesto de Florianópolis sobre a competência em informação e as populações vulneráveis e minorias. Florianópolis, 2013. Anais eletrônicos... Florianópolis, 2013. Disponível em: http://febab.org.br/manifesto florianopolis portugues.pdf. Acesso em: 15 jun. 2018.

FLORIDI, L. The informational nature of personal identity. Minds and machines, v. 21, n. 4, p. 549, 2011. Disponível em: https://philpapers.org/rec/FLOTIN. Acesso em: 14 out. 2018.

FURTADO, R. L.; BELLUZZO, R. C. B. Gestão do conhecimento e Competência em informação: possíveis relações e perspectivas de atuação do profissional arquivista. Informação \& Informação, Londrina, v. 23, n. 2, p. 314-339, 2018.Disponível em:

http://www.uel.br/revistas/uel/index.php/informacao/article/view/28881. Acesso em 3 dez. 2018.

FURTADO, R. L.; BELLUZZO, R. C. B.; PAZIN, M. C. C. Competência em Informação e Arquivologia: uma revisão bibliográfica sistemática no cenário nacional e internacional. In: ENCONTRO NACIONAL DE PESQUISA EM CIÊNCIA DA INFORMAÇÃO, 17., Salvador, 2016. Anais... Salvador: UFBP, 2016. Disponível em: http://www.brapci.inf.br/index.php/article/download/50136. Acesso em: 30 ago. 2018

FURTADO, R. L.; BELLUZZO, R. C. B.; VITORIANO, M. C. C. P. Arquivologia e Competência em informação: possíveis conexões por meio da abordagem à literatura internacional. In: ENCONTRO NACIONAL DE PESQUISA EM CIÊNCIA DA INFORMAÇÃO, 19., Londrina, 2018.

Anais... Londrina: UEL, 2018. Disponível em:

http://enancib.marilia.unesp.br/index.php/XIXENANCIB/xixenancib/paper/view/1352. Acesso em: 20 dez. 2018

FURTADO, R. L.; PAZIN, M. C. C.; BELLUZZO, R. C. B. A competência em informação na formação em Arquivologia. In: ENCONTRO NACIONAL DE PESQUISA EM CIÊNCIA DA INFORMAÇÃO, 18., Marília: UNESP, 2017. Anais eletrônicos... Marília: Unesp, 2017. Disponível em: http://enancib.marilia.unesp.br/index.php/xviiienancib/ENANCIB/paper/view/355. Acesso em: 30 ago. 2018

GASQUE, K. C. G. D. O pensamento reflexivo na busca e no uso da informação. In: ENCONTRO NACIONAL DE PESQUISA EM CIÊNCIA DA INFORMAÇÃO, 7., 2006, Marília/SP. Anais... Marília: Unesp, 2006. p. 432-440. Disponível em: 
http://enancib.ibict.br/index.php/enancib/viienancib/paper/viewFile/2469/1600. Acesso em: 20 mar. 2018.

GONÇALVES, R. B.; GODINHO, N. B. Práticas de pesquisa de estudantes de Biblioteconomia e Arquivologia: uma abordagem sobre os aspectos afetivos envolvidos e a competência informacional. Revista Brasileira de Educação em Ciência da Informação, v.1, n.1, p.75-93, jan./jun. 2014. Disponível em: http://www.abecin.org.br/revista/index.php/rebecin/article/view/6/pdf 6. Acesso em: 29 set. 2018.

HATSCHBACH, M. H. L. Information literacy: aspectos conceituais e iniciativas em ambiente digital para o estudante de nível superior. 2002. 108f. Dissertação (Mestrado em Ciência da Informação) - Universidade Federal do Rio de Janeiro/Escola de Economia/Ministério da Ciência e Tecnologia/Instituto Brasileiro em Informação, Ciência e Tecnologia, Rio de Janeiro, 2002. Disponível em: http://tede-dep.ibict.br/bitstream/tde/49/1/mariahelena2002.pdf. Acesso em: 10 jul. 2016.

HIGH-LEVEL Colloquium on Information Literacy and Lifelong Learning Final Report. Alexandria: UNESCO/NFIL/IFLA, 2006. Disponível em: www.ifla.org/files/assets/informationliteracy/publications/high-level-colloquium. Acesso em: 2 nov. 2018.

HORTON JUNIOR, F. W. (Ed.). Overview of information literacy resources worldwide. Paris: Unesco, 2013.

HORTON JUNIOR, F. W. Understanding information literacy: a primer. Paris: UNESCO, 2007.

HORTON, JUNIOR, F. W. Overview of information literacy: resources worldwide. 2. ed. Paris: UNESCO, 2014/2015. Disponível em: http://infolit.org/unescos-overview-of-informationliteracy-resources-worldwide-2nd-ed-2014-2015/. Acesso em: 02 maio 2018.

LEMIEUX, V.; SMITH, T. D. Leveraging archival theory to develop a taxonomy of online disinformation. 2018 IEEE International Conference on Big Data, Seattle, WA, USA, 2018, pp. 4420-4426. Disponível em https://ieeexplore.ieee.org/document/8622391/authors\#authors. Acesso em: 12 jan. 2019.

MARTENDAL, F. F.; SILVA, E. C. L.; VITORINO, E. V. Diálogo entre as dimensões da Competência em informação e os cursos de graduação em Arquivologia do sul do Brasil. Em Questão, v. 23, n. 3, p. 53-78, 2017.Disponível em:

https://seer.ufrgs.br/EmQuestao/article/view/69952/41370. Acesso em: 18 ago. 2018.

MENEZES, P. L.; VITORINO, E. V. A Competência Informacional fundamentada na dimensão ética. Em Questão, v. 20, n. 2, p. 86-107, 2014. Disponível em:

https://seer.ufrgs.br/EmQuestao/article/view/46044/32151. Acesso em: 19 ago. 2018.

MORENO, N. A. A informação arquivística e o processo de tomada de decisão. Informação \& sociedade: Estudos, v. 17, n. 1, 2007. Disponível em:

http://periodicos.ufpb.br/index.php/ies/article/view/483. Acesso em: 7 abr. 2018. 
PINHEIRO, L. V. R.; FERREZ, H. D. Tesauro brasileiro de Ciência da Informação. Rio de Janeiro: IBICT, 2014.

OTTONICAR, S. L. C. Análise teórico-descritiva da competência em informação de gestores como fator de competitividade das indústrias de eletroeletrônicos da cidade de Garça/SP. 2016. Dissertação (Mestrado em Ciência da Informação) - Faculdade de Filosofia e Ciências, Universidade Estadual Paulista, Marília, 2016. Disponível em:

https://repositorio.unesp.br/handle/11449/138034. Acesso em: 17 mar 2018.

RIBEIRO, F.; SILVA, A. M. A Mudança de paradigma na formação BAD - um modelo formativo para a Ciência da Informação. Actas do Congresso Nacional de Bibliotecários, Arquivistas e Documentalistas, n. 7, 2001. Disponível em:

https://www.bad.pt/publicacoes/index.php/congressosbad/article/view/694/693. Acesso em: 22 jan. 2019.

ROUSSEAU, J. Y.; COUTURE, C. Os fundamentos da disciplina arquivística. Lisboa: Publicações Dom Quixote, 1998.

SCHMIDT, C. M. S. Arquivologia e a construção do seu objeto científico: concepções, trajetórias, contextualizações. 2012. 320f. Tese (Doutorado em Ciência da Informação). Universidade de São Paulo, Escola de Comunicação e Artes, 2012. Disponível em:

http://www.teses.usp.br/teses/disponiveis/27/27151/tde-02072013-170328/en.php. Acesso em: 21 set 2018.

UNESCO - ORGANIZAÇÃO DAS NAÇÕES UNIDAS PARA A EDUCAÇÃO, A CIÊNCIA E A CULTURA. The Prague Declaration "Towards an Information Literate Society". Praga: UNESCO, 2003.

UNIVERSIDADE ESTADUAL PAULISTA; UNIVERSIDADE DE BRASÍLIA; INSTITUTO BRASILEIRO DE INFORMAÇÃO EM CIÊNCIA E TECNOLOGIA. Carta de Marília sobre Competência em Informação. 2014. Disponível em:

http://www.lti.pro.br/userfiles/downloads/CARTA de Marilia.pdf. Acesso em: 22 jan. 2019.

VITORINO, E. V.; PIANTOLA, D. Competência informacional - bases históricas e conceituais: construindo significados. Ciência da Informação, v. 38, n. 3, 2009. Disponível em: http://revista.ibict.br/ciinf/article/view/1236/1414. Acesso em: 22 jun. 2018.

YAFUSHI, C. A. P. A Competência em informação para a construção de conhecimento no processo decisório: estudo de caso na Duratex de Agudos (SP). 2015. 232 f. Dissertação (Mestrado) - Universidade Estadual Paulista Júlio de Mesquita Filho, Faculdade de Filosofia e Ciências, 2015. Disponível em: https://repositorio.unesp.br/handle/11449/126599. Acesso em: 13 jun. 2018.

ZATTAR, M. Competência em Informação e Desinformação: critérios de avaliação do conteúdo das fontes de informação. Liinc em Revista, v. 13, n. 2, 2017. Disponível em: http://revista.ibict.br/liinc/article/view/4075/3385. Acesso em: 13 jun. 2018.

ZURKOWSKI, P. G. Information services environment relationships and priorities. Washington D.C.: National Commission on Libraries, 1974. 